\title{
Achromatic color matching as a function of apparent target orientation, target and background luminance, and lightness or brightness instructions
}

\author{
GORDON M. REDDING and CHARLES F. LESTER \\ Illinois State University, Normal, Illinois 61761
}

\begin{abstract}
In two experiments, achromatic color matches for a fixed target, under constant illumination, were compared under conditions where the target appeared perpendicular to illumination direction and coplanar with the background (monocular viewing) and where the target appeared nonperpendicular to illumination direction and noncoplanar with the background (binocular viewing). Contrary to the coplanar ratio hypothesis, which predicts a "lightening" of the target seen coplanar with a darker background, a general "darkening" of the target occurred for both white (N9.5/) and black (N3/) backgrounds and for both dark (N5.5/) and light (N6.5/) targets. This darkening effect was greatest for the darker target and black background, and approximately equal for other combinations of target value and background. The direction of the darkening effect is consistent with the albedo hypothesis, which assumes an inferential correction for changes in conditions of illumination. However, variation in the magnitude of the darkening effect is problematical, and cannot be easily explained by any existing theory. In both experiments, instructions to judge "lightness" or "brightness" failed to produce any substantial differences in performance, although postexperimental questioning suggested that subjects had a verbal understanding of these concepts. Apparently, under reduction conditions, subjects lack cues to illumination and make only lightness matches, regardless of instructions.
\end{abstract}

The intensity of reflected light reaching the retina varies as conditions of illumination for an object change. Despite such changes in the proximal stimulus, the perception of achromatic surface color remains approximately constant and veridical over large changes in conditions of illumination. A piece of paper looks white and a lump of coal looks black in both direct sunlight and shadow. These basic facts of perceptual constancy have long been known (e.g., Feldman \& Weld, 1939), and they demonstrate that perception does not depend only on isolated, local characteristics of stimulation, but rather on the total context in which particular stimuli are presented. Two general theoretical positions have been developed to explain how the perceptual system accomplishes this integration of contextual and target information.

Inferential cue theory seeks to identify the sources of information critical to illumination (e.g., surface orientation relative to illumination source) that may be used to "adjust" simple surface luminances to take into account change in conditions of illumination. For instance, the albedo hypothesis (Woodworth \& Schlosberg, 1955) accounts for constancy with a "computational" process which discounts changes in

Reprint requests should be addressed to Gordon M. Redding, Department of Psychology, Illinois State University, Normal, Illinois 61761 . luminance by registering illumination changes, the ratio of luminance to illumination (albedo) being invariant for a given surface color. The albedo hypothesis is a version of the more general invariance hypothesis which has been applied to size constancy (Epstein, Park, \& Casey, 1961) and shape constancy (Epstein \& Park, 1963). The processing of psychological variables is assumed to mirror the geometric invariance between physical correspondents. Because of the unconscious inference (Helmholtz, 1866/1962) implied, this position has been characterized as "cognitive" in nature.

Stimulus invariance theory seeks to identify invariant "higher order" relationships among simple stimulus variables that correlate with phenomenal experience. For instance, Wallach's $(1948,1963)$ contrast or ratio hypothesis attributes constancy to the fact that changes in overall illumination level produce proportional changes in luminance for all surfaces in the visual field. The ratios among surface luminances remain constant regardless of illumination level. The ratio hypothesis is in the tradition of ecological theories (Gibson, 1950, 1966; Shaw \& Bransford, 1977), which locate the basis for constancy directly in the stimulus array.

The strongest support for a cognitive explanation of achromatic color perception is provided by studies which show effects of perceived target orientation relative to the illumination source (e.g., Beck, 1965; 
Flock \& Freedburg, 1970; Hochberg \& Beck, 1954). A fixed target, under constant illumination, is judged darker when made to appear perpendicular to the direction of illumination, and therefore not in shadow, than when it is perceived correctly to be parallel to the direction of illumination and therefore as standing in shadow. However, illumination judgments tend to be unreliable and constancy in the perception of achromatic color can be obtained from people who make inaccurate judgments of incident illumination (Beck, 1959, 1961). Moreover, orientation effects do not always occur (e.g., Epstein, 1961), and when they do they are invariably small in magnitude, no more than .5 on the Munsell scale (Beck, 1972; Flock \& Freedburg, 1970).

Strongest support for a stimulus explanation of achromatic color perception is given by studies which show that targets appearing on different backgrounds are judged to have the same color when the ratios of target to background luminance match (e.g., Hess \& Pretori, 1894; Wallach, 1948, 1963). The perceived achromatic color of a target remains constant when the luminance ratio of the target surface to other surfaces in the field of view remains constant. However, the luminance ratio principle applies only for a limited range of ratio and luminance values (Hess \& Pretori, 1894; Hurvich \& Jameson, 1966; Jameson \& Hurvich, 1961). Moreover, the effectiveness of a surround on the perceived achromatic color of a target decreases with increasing depth between the two surfaces (Gogel \& Mershon, 1969; Mershon \& Gogel, 1970). The luminance ratio principle applies only when target and background appear to be coplanar (Gilchrist, 1977; Rock, 1977).

Thus, available evidence is equivocal with respect to cognitive or stimulus explanations of achromatic color perception. The present study attempted a clearer test between these two hypotheses. Under conditions in which apparent target orientation changes relative to the direction of illumination, the two theoretical positions seem to make different predictions, depending upon whether the background is lighter or darker than the target.

Cognitive theory makes the same predictions for changes in apparent target orientation when background is both lighter and darker than the target. A fixed target, under constant illumination, should be judged darker when made to appear perpendicular to the direction of illumination than when it is perceived correctly to be nonperpendicular to the direction of illumination. Target luminance should be greater when it is seen perpendicular to the illumination source, but since there is no difference in luminance (no real change in orientation), the logical inference is that the surface color of the target is darker. While the magnitude of the predicted "darkening" effect may vary depending upon background luminance, the direction of the effect should be the same, regardless of background.
Stimulus theory makes differential predictions for changes in apparent target orientation when background is lighter or darker than the target. If the target appears coplanar with the background when it is made to appear perpendicular to the illumination source, contrast effects should be increased compared with the condition in which the target appears noncoplanar and nonperpendicular to the source. Consequently, when the background is lighter than the target, perceiving the target perpendicular to the source and coplanar with the background should produce a darkening effect, but when the background is darker than the target, a lightening effect is predicted. Of course, if spatial orientation is not a critical variable in achromatic color perception, there should be no difference in color perception between orientation conditions.

In the present experiments, the conditions necessary to test these predictions were realized by front illumination of a target fixed on a vertical background, which was either lighter or darker than the target. The target was always a trapezoid, slanted top toward the subject, constructed such that it produced a projective square shape. Apparent orientation was manipulated by varying viewing conditions, binocular or monocular. Subjects made judgments by selecting a matching Munsell chip from a comparison series which appeared below and on the same background as the target.

Another variable of interest was whether subjects were instructed to match the target in terms of "lightness" or "brightness." These terms refer to different phenomenal characteristics of perception. Brightness describes the intensity of light reflected from a surface, while lightness refers to the surface color. In the normal situation, it is lightness which remains constant and brightness which changes with changes in illumination. White paper in sunlight appears brighter but not lighter than it does in shadow. Similarly, a piece of coal appears brighter but not lighter (Rock, 1975). Thus, the concern in the present experiments was with lightness judgments. However, the terms "lightness" and "brightness" are sufficiently ambiguous in common usage that subjects might interpret them in either phenomenal sense. Moreover, brightness judgments seem to depend upon structural cues for the intensity of illumination (Beck, 1974), and the absence of such cues in the usual abstracted laboratory situation may produce unreliable judgments if subjects interpret instructions to mean that brightness judgments are required. Thus, both kinds of instructions were included in the present experiments to provide a check on subjects' interpretations.

\section{EXPERIMENT 1}

\section{Method}

Subjects. The 60 subjects were undergraduate, male and female, volunteers who received course credit for participation. All subjects had normal or corrected-to-normal vision. 
Apparatus. All stimulus events occurred in a reduction tunnel, $8 \mathrm{ft}$ long $(2.4 \mathrm{~m}) \times 4 \mathrm{ft}$ wide $(1.2 \mathrm{~m}) \times 2 \mathrm{ft}$ high $(.6 \mathrm{~m})$. The interior of the tunnel was covered with nonreflecting black felt and illuminated by a standard $75-\mathrm{W}$ light bulb located on the interior front wall of the box, 10 in. $(25.4 \mathrm{~cm})$ above the subject's eye. The subject viewed the stimulus through an opening in the front wall which restricted the field of view to the interior of the box. A head-chinrest and an eyepatch were employed to minimize depth cues in the monocular viewing conditions.

Materials. The target was a trapezoid shape, covered with N5.5/ Munsell paper and mounted in the center of the back wall of the tunnel at a $45-\mathrm{deg}$ angle (top toward the subject) on a $40 \times 22$ in. $(101.6 \times 55.9 \mathrm{~cm})$ background that was either white or black (approximately $\mathrm{N} 9.5$ / and $\mathrm{N} 3 /$, respectively). The trapezoid measured 3.5 in. $(8.9 \mathrm{~cm})$ across the top, $3.75 \mathrm{in} .(9.5 \mathrm{~cm})$ along the bottom, and $5.5 \mathrm{in.}(14.0 \mathrm{~cm})$ in height. Projectively, the target appeared as a square, coplanar with the background.

A comparison series of Munsell chips (1970 edition) was located 4 in. $(10.2 \mathrm{~cm})$ below the bottom of and on the same background as the target. This series ranged from $\mathrm{N} 7 /$ to $\mathrm{N} 2.50$ / (right to left), in N.25/ steps. To facilitate response report, the comparison chips were assigned the numbers $1-19$ (right to left), printed immediately below each chip.

Design. Initially, four independent groups of nine subjects each were tested, with treatment being defined by combinations of viewing condition (monocular or binocular) and background order (black then white or white then black), and with instructions to match the target in "brightness." The subjects were assigned randomly to groups, and three successive trials were given with each background. Subsequently, four additional groups of six subjects each were tested, the only change being substitution of the term "lightness" or "brightness" in the instructions.

Procedure. On each trial, the stimulus array was exposed by removing an occluder panel. Subjects viewed the target and comparison series, and reported the number of the comparison chip that matched the target. The occluder was then replaced while response was recorded and when the background was changed after three trials. No time limit was placed on judgment, but response was usually made quickly, the average time for the entire experimental session being approximately $15 \mathrm{~min}$. After the six trials were completed, all subjects answered a questionnaire to determine whether they had seen the object as coplanar with the background or tilted. Four subjects in the monocular viewing condition who did not report seeing the target as coplanar were replaced.

\section{Results and Discussion}

An unequal " $n$ " analysis of variance, performed on responses expressed as Munsell values, revealed a substantial main effect for viewing conditions $[F(1,56)$ $=23.11, \mathrm{p}<.001]$. The expected "darkening" effect appeared, with subjects viewing the target monocularly, producing a mean judgment of $\mathrm{N} 5.24 \%$, while subjects viewing the target binocularly, on the average, judged the target to be lighter (N5.55/) by slightly more than .25 a Munsell step (.31).

Figure 1 shows how the effect of viewing conditions varied as a function of background. Contrary to expectation from a simple contrast position, the darkening effect was greatest with the black background $[F(1,56)=17.50, p<.001]$, although the presence of contrast effects is indicated by the fact that, on the average, the target on a white background was judged darker (N4.94/) than on a black background (N5.85/) $[F(1,56)=202.07, p<.001]$. The only other significant source of variance was the interaction of instruc-

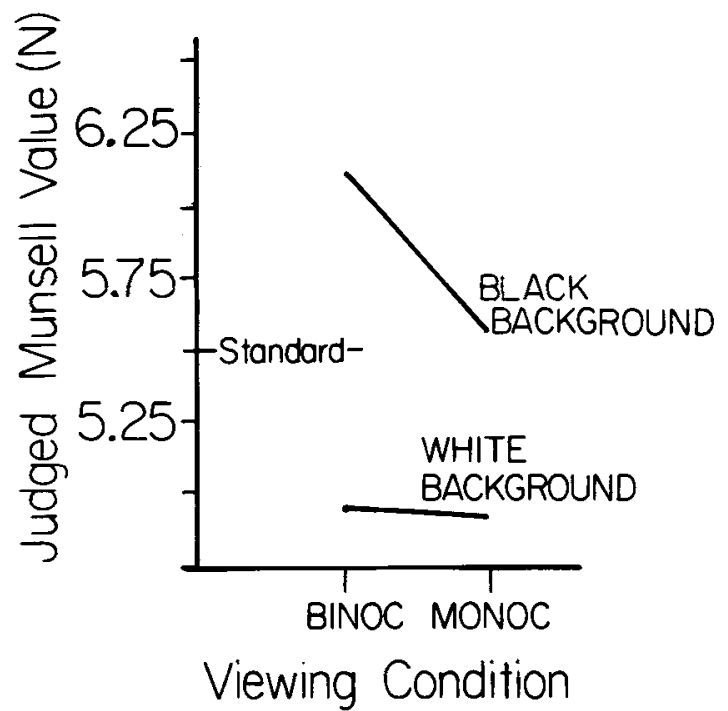

Figure 1. The average neutral Munsell value (N) selected as matching the N5.5/ target (standard) used in Experiment 1, as a function of background and viewing condition.

tions and backgrounds $[F(1,56)=4.53, p<.05]$. The mean judgments under lightness instructions, for black and white backgrounds, respectively, were $\mathrm{N} 5.75 /$ and $\mathrm{N} 5.02 /$, and the corresponding values for brightness instructions were N5.92/ and N4.90/. Thus, the contrast effects of the two backgrounds seem to be greater with brightness than with lightness instructions. However, this may be a sampling difference, since subjects receiving lightness instructions were all run subsequent to those receiving the brightness instructions. The three-way interaction of viewing conditions, backgrounds, and instructions was not significant $[F(1,56)=2.26]$. Apparently, subjects were unable to make brightness judgments under the reduced cue conditions, and the responses of all subjects seem to reflect lightness judgments.

\section{EXPERIMENT 2}

\section{Method}

In the second experiment, several improvements were made on the method employed in the first experiment. First, in addition to the N5.5/ target, a second, lighter (N6.5/) target was tested, thereby increasing the range of target-10-background luminance ratios. Second, the upper (white) limit of the comparison series was increased by starting the 19-unit series at N3.25/ and increasing, in .25 steps, up to $\mathrm{N} 7.75 \%$. This change was made because a few subjects in the first experiment suggested that they might have responded with a lighter match if one had been available. Third, instructions were made a "proper" variable in Experiment 2. The 160 subjects, from the same source as Experiment 1 , were randomly assigned, 10 to each of the 16 treatment groups defined by factorial combination of target value, viewing condition, instruction, and background order. In all other respects the design and materials were the same as for the first experiment.

Also in Experiment 2, a more concerted effort was made to communicate the sense of "lightness" and "brightness" instructions. Carefully worded instructions, together with examples, were 
given the subjects (see Appendix 1). In addition, the subject's understanding of the difference between the two kinds of judgment was tested both before ( 2 questions) and after (14 questions) experimentation (see Appendix 2). In addition to postexperimental questioning about the target orientation, the subjects were quizzed concerning the perceived shape of the target. Responses to these questions were recorded and treated as ancillary data.

Finally, the length of the reduction tunnel was shortened to $6 \mathrm{ft}(1.8 \mathrm{~m})$. In other respects, the apparatus and procedure were similar to those of Experiment 1.

\section{Results and Discussion}

Table 1 shows the data for postexperimental test for understanding of the concepts of lightness and brightness. Subjects' performance was above chance in answering questions which tested for lightness and brightness (seven questions each), showing about $75 \%$ correct response. There is a tendency for performance to be best on lightness questions, particularly for those subjects receiving monocular viewing of the lighter target with lightness instructions. However, there are no great differences among the treatment groups, and these data indicate that subjects had at least a moderately good verbal understanding of the concepts.

Table 2 shows the results for postexperimental questioning concerning the perceived shape and orientation of the target. As can be seen, most subjects reported the requisite target orientation, although slightly more monocular subjects reported a flat target than did binocular subjects report a tilted target. Similarly, shape reports were more satisfactory for monocular subjects than for binocular subjects, but this difference is entirely due to the low frequency of acceptable shape reports for subjects receiving brightness instructions. About half of the time, binocular subjects who received brightness instructions reported such distant shapes as triangle, rectangle, and square. An explanation of this finding is not immediately apparent, but it seems clear that these subjects experienced more ambiguity about target shape than subjects in the other treatment groups. However, taken as a whole, the results of postexperimental questioning support the conclusion that conditions necessary to test the hypotheses were established by the experimental arrangement.
Table 1

\begin{tabular}{|c|c|c|c|c|c|c|c|}
\hline \multirow[b]{2}{*}{ Instructions } & \multicolumn{3}{|c|}{ Dark Target $(5.5 \mathrm{~N})$} & \multicolumn{3}{|c|}{ Light Target $(6.5 \mathrm{~N})$} & \multirow[b]{2}{*}{ Mean } \\
\hline & B & $\mathbf{M}$ & Mean & B & $\mathbf{M}$ & Mean & \\
\hline & \multicolumn{7}{|c|}{ Brightness Questions } \\
\hline $\begin{array}{l}\text { Brightness } \\
\text { Lightness }\end{array}$ & $\begin{array}{l}77 \\
71\end{array}$ & $\begin{array}{l}73 \\
80\end{array}$ & $\begin{array}{l}75 \\
76\end{array}$ & $\begin{array}{l}74 \\
79\end{array}$ & $\begin{array}{l}74 \\
79\end{array}$ & $\begin{array}{l}74 \\
79\end{array}$ & $\begin{array}{l}74 \\
78\end{array}$ \\
\hline \multirow[t]{2}{*}{ Mean } & 74 & 76 & 75 & 76 & 76 & 76 & 76 \\
\hline & \multicolumn{7}{|c|}{ Lightness Questions } \\
\hline $\begin{array}{l}\text { Brightness } \\
\text { Lightness }\end{array}$ & $\begin{array}{l}74 \\
70\end{array}$ & $\begin{array}{l}70 \\
80\end{array}$ & $\begin{array}{l}72 \\
75\end{array}$ & $\begin{array}{l}71 \\
76\end{array}$ & $\begin{array}{l}74 \\
84\end{array}$ & $\begin{array}{l}72 \\
80\end{array}$ & $\begin{array}{l}72 \\
78\end{array}$ \\
\hline \multirow[t]{2}{*}{ Mean } & 72 & 75 & 74 & 74 & 79 & 76 & 75 \\
\hline & \multicolumn{7}{|c|}{ Averages } \\
\hline $\begin{array}{l}\text { Brightness } \\
\text { Lightness }\end{array}$ & $\begin{array}{l}76 \\
71\end{array}$ & $\begin{array}{l}71 \\
80\end{array}$ & $\begin{array}{l}74 \\
76\end{array}$ & $\begin{array}{l}73 \\
77\end{array}$ & $\begin{array}{l}74 \\
81\end{array}$ & $\begin{array}{l}74 \\
79\end{array}$ & $\begin{array}{l}74 \\
78\end{array}$ \\
\hline Mean & 74 & 76 & 75 & 75 & 78 & 76 & 76 \\
\hline
\end{tabular}

Note $-B=$ binocular; $M=$ monocular. Mean data are shown for combinations of target value, viewing condition, and instruction, and separately for, as well as averaged over, questions testing brightness and lightness.

Analysis of variance, performed on the judgment Munsell values, revealed a significant darkening effect for viewing conditions $[\mathrm{F}(1,152)=19.43, \mathrm{p}<.001]$ similar to that found in Experiment 1. Binocular viewing yielded a mean judgment of N6.03/, while monocular viewing produced a mean judgment of $\mathrm{N} 5.81$, a darkening of about .22 Munsell steps. Also like the first experiment, darker judgments were made with the white background $(\overline{\mathrm{X}}=\mathrm{N} 5.65 /)$ than with the black background $(\bar{X}=\mathrm{N} 6.19 /)[\mathrm{F}(1,152)=164.11$, $\mathrm{p}<.001$ ]. As can be seen in Figure 2, the present data further replicated the first experiment in showing a larger darkening effect for the black background $[F(1,152)=12.18, p<.001]$, but this effect was restricted to the darker $(\mathrm{N} 5.5 /)$ target $[\mathrm{F}(1,152)=$ $7.56, \mathrm{p}<.01]$. Overall, the lighter (N6.5/) target produced lighter judgments $[\mathrm{F}(1,152)=372.66$, $\mathrm{p}<.001]$, smaller darkening effects $[\mathrm{F}(1,152)=4.23$, $\mathrm{p}<.05]$, and increased differences in judgment between, backgrounds $[F(1,152)=16.06, p<.001]$. Al-

Table 2

Percent of Subjects Reporting Acceptable Percepts of Target Shape and Orientation as a Function of Target Value, Viewing Condition, and Instruction

\begin{tabular}{|c|c|c|c|c|c|c|c|c|c|c|c|c|}
\hline \multirow[b]{3}{*}{ Instructions } & \multicolumn{4}{|c|}{$5.5 \mathrm{~N}$ Target } & \multicolumn{4}{|c|}{ 6.5 N Target } & \multicolumn{4}{|c|}{ Mean } \\
\hline & \multicolumn{2}{|c|}{ Binocular } & \multicolumn{2}{|c|}{ Monocular } & \multicolumn{2}{|c|}{ Binocular } & \multicolumn{2}{|c|}{ Monocular } & \multicolumn{2}{|c|}{ Binocular } & \multicolumn{2}{|c|}{ Monocular } \\
\hline & TR & TL & SQ & FT & TR & TL & SQ & FT & TR & TL & SQ & FT \\
\hline $\begin{array}{l}\text { Brightness } \\
\text { Lightness }\end{array}$ & $\begin{array}{l}50 \\
75\end{array}$ & $\begin{array}{l}85 \\
80\end{array}$ & $\begin{array}{l}70 \\
70\end{array}$ & $\begin{array}{l}95 \\
85\end{array}$ & $\begin{array}{l}50 \\
80\end{array}$ & $\begin{array}{l}90 \\
85\end{array}$ & $\begin{array}{l}75 \\
75\end{array}$ & $\begin{array}{l}90 \\
95\end{array}$ & $\begin{array}{l}50 \\
78\end{array}$ & $\begin{array}{l}88 \\
82\end{array}$ & $\begin{array}{l}72 \\
72\end{array}$ & $\begin{array}{l}92 \\
90\end{array}$ \\
\hline Mean & 62 & 82 & 70 & 90 & 65 & 88 & 75 & 92 & 62 & 85 & 72 & 91 \\
\hline
\end{tabular}

Note-For binocular viewing, acceptable percepts are tilted (TL) trapezoids or rectangles (TR). For monocular viewing, an acceptable percept is a flat (FT) square (SQ). 


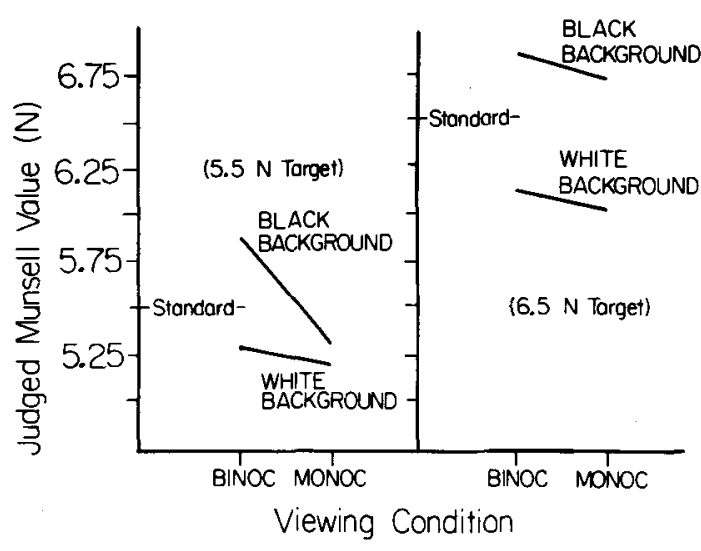

Figure 2. The average neutral Munsell value (N) selected as matching the target (standard) in Experiment 2, as a function of target value, background, and viewing condition.

though the darkening effect of viewing conditions was always greater for the N5.5/ target, the effect increased in magnitude with trials for both targets and showed a greater increase for the darker $(\mathrm{N} 5.5 /)$ target $[\mathrm{F}(2,304)$ $=2.12, \mathrm{p}<.05]$.

The only remaining significant sources of variance to be discussed are two interactions involving instructions. Like the first experiment, instructions interacted with backgrounds $[\mathrm{F}(1,152)=5.32, \mathrm{p}<.025]$, but the nature of this interaction was opposite to the direction found in Experiment 1. The mean judgments under lightness instructions, for black and white backgrounds, respectively, were N6.26/ and N5.63/, and the corresponding values for brightness instructions were N6.11/ and N5.67/. Thus, any difference in contrast effects as a function of instructions is unreliable, and the interaction of these variables is probably a chance occurrence. Finally, brightness instructions tended to produce very slightly darker judgments of the N5.5/ target on the first trial, but this effect disappeared by the third trial; for the N6.5/ target the reverse tendency appeared, with lightness instructions yielding darker judgments and the difference decreasing with successive trials $[F(2,304)=$ $3.31, \mathrm{p}<.05]$. However, these effects are small in magnitude and may be due to random error. Thus, this experiment is consistent with Experiment 1 in showing no substantial differences in performance as a function of instructions.

\section{CONCLUSIONS}

On the whole, the present data lend qualitative support to an inferential cue theory of lightness constancy. The effect of viewing conditions was almost invariably a darkening of perceived target color, although the magnitude of this effect depends upon the particular combination of target value and background. The fact that spatial arrangement affects perceived achromatic color substantiates previous findings (e.g.,
Beck, 1965; Flock \& Freedburg, 1970; Hochberg \& Beck, 1954) and argues against an explanation of lightness perception simply in terms of luminance ratios among areas of the proximal stimulus. Moreover, the weaker assumption that the ratio principle applies only for surfaces which are perceived to be coplanar (Gilchrist, 1977) does not seem to be tenable. The darkening effect when the darker (N5.5/) target was seen coplanar with the black background (monocular viewing) is opposite to the direction predicted by a ratio hypothesis, and when darkening is predicted to be greatest from contrast effects (i.e., white background), the effect was actually smaller in magnitude.

The tendency for changes in perceived spatial arrangement to evoke changes in perceived lightness in the same direction regardless of background is consistent with previous studies, but the interaction of target value and background appears to be unusual. For instance, Beck (1965) found darkening effects to be equal in magnitude (N.5/) for both black and white backgrounds using a dark target $(9.4 \%$ reflectance, or approximately N3.6/ on the Munsell scale). Thus, the available data suggests that the darkening effect is equal in magnitude for both backgrounds with dark targets (e.g., N3.6/), and remains substantial for intermediate target values (e.g., N5.5/) with a black background, but is markedly reduced with a white background. For light targets (e.g., N6.5/), the effect virtually disappears for both black and white backgrounds. In sum, the darkening effect appears to decrease with increasingly lighter targets, but this decrease in magnitude is greater for white backgrounds.

Although a cognitive theory such as the albedo hypothesis can explain the direction of the darkening effect, it cannot handle the variation in magnitude with changes in target value and background. Cognitive theory itself does not include any mechanism to account for such variation. However, Beck (1965, 1972) has argued that the perception of target orientation is only one of a number of central organizational processes which determine when a change in luminance will be seen as a difference in illumination or as a difference in lightness. The input to such organizational processes is the intensity response of peripheral mechanisms, and variation in such input may produce different perceptual organizations.

In the present case, low-intensity targets may be interpreted as heavily shadowed when the target is perceived turned away from the light source and as a darker surface when the target is seen facing the light. High-intensity targets may evoke an organization calling for lighter shadows and lighter surfaces. Thus, the darkening effect would generally be less for higher intensity targets. However, differences in background may be interpreted as differences in illumination level. For instance, a white background may evoke an organization calling for high illumination, with the result that even relatively low-intensity targets are seen 
as lightly shadowed when slanted and as lighter in color when facing the light. Consequently, the darkening effect would decrease at lower target intensities with a white background than with a black background. However, direct tests are necessary before confidence can be placed in this admittedly ad hoc explanation.

In retrospect, the absence of substantial effects for instructions is not surprising. Subjects generally find it difficult to make brightness judgments in the absence of normal cues to illumination (e.g., Beck, 1974), and a number of studies (e.g., Henneman, 1935; Thouless, 1932) have found subjects unable to distinguish between brightness and lightness in a simplified visual field. Thus, it seems reasonable to assume that subjects in the present experiments were unable to make brightness judgments, and instead reported judgments of lightness.

\section{REFERENCES}

Beck, J. Stimulus correlated for the judged illumination of a surface. Journal of Experimental Psychology, 1959, 58, 267-274.

BECK, J. Judgments of surface illumination and lightness. Journal of Experimental Psychology, 1961, 61, 368-373.

BECK, J. Apparent spatial position and the perception of lightness. Journal of Experimental Psychology, 1965, 69, 170-179.

ВЕск, J. Surface color perception. Ithaca, N. Y: Cornell University Press, 1972.

BECK, J. Dimensions of an achromatic surface color. In R. B. MacLeod \& H. L. Pick, Jr. (Eds.), Perception: Essays in honor of James J. Gibson. Ithaca, N.Y: Cornell University Press, 1974.

Epstein, W. Phenomenal orientation and perceived achromatic color. Journal of Psychology, 1961, 52, 51-53.

EPstein, W., \& Park, J. Shape constancy: Functional relationships and theoretical formulations. Psychological Bulletin, $1963,60,265-288$.

Epste in, W., Park, J., \& Casey, A. The current status of the size-distance hypothesis. Psychological Bulletin, 1961, 58, 491-514.

Feldman, S., \& Weld, H. P. Perception. In E. G. Boring, H. S. Langfeld, \& H. P. Weld (Eds.), Introduction to psychology. New York: Wiley, 1939.

Flock, H. R., \& Freedburg, E. Perceived angle of incidence and achromatic surface color. Perception \& Psychophysics, 1970, 8, 251-256.

Gibson, J. J. The perception of the visual world. Boston: Houghton Mifflin, 1950.

GiBson, J. J. The senses considered as perceptual systems. Boston: Houghton Mifflin, 1966

Gilchrist, A. L. Perceived lightness depends on perceived spatial arrangement. Science, 1977, 195, 185-187.

Gogel, W. C., \& Mershon, D. H. Depth adjacency and simultaneous contrast. Perception \& Psychophysics, 1969, 5, 13-17.

Helmholtz, H. von. [Treatise on physiological optics (Yol.3)] (trans. from the 3 rd German ed., J. P. C. Southall). New York: Dover, 1962. (Originally published 1866)

HENNEMAN, R. H. A photometric study of the perception of object color. Archives of Psychology, 1935, No. 179.

Hess, C., \& Pretori, H. Messende Untersuchungen über die Gesetzmässigkeit des simultanen Helligkeits-Contrastes. Archiv für Ophthalmologie, 1894, 40, 1-24. (Cited by Hurvich, L. M., \& Jameson, D., The perception of brightness and darkness. Boston: Allyn \& Bacon, 1966.)
Hochberg, J. E., \& Beck, J. Apparent spatial arrangement and perceived brightness. Journal of Experimental Psychology, 1954, 47, 263-266.

Hurvich, L. M., \& Jameson, D. The perception of brightness and darkness. Boston: Allyn \& Bacon, 1966.

Jameson, D., \& Hurvich, L. M. Complexities of perceived brightness. Science, 1961, 133, 174-179.

Mershon, D. H., \& Gogel, W. C. Effects of stereoscopic cues on perceived whiteness. American Journal of Psychology, 1970 , 83, 55-67.

Rock, I. An introduction to perception. New York: Macmillan, 1975.

Rock, I. In defense of unconscious inference. In W. Epstein (Ed.), Stability and constancy in visual perception: Mechanisms and processes. New York: Wiley, 1977.

Syaw, R., \& Bransford, J. (Eds.). Perceiving, acting and knowing: Toward an ecological psychology. Hillsdale, N.J: Erlbaum, 1977.

Thouless, $R$. H. Individual differences in phenomenal regression. British Journal of Psychology, 1932, 22, 216-241.

WALLACK, $\mathrm{H}$. Brightness constancy and the nature of achromatic colors. Journal of Experimental Psychology, 1948, 38, 310-324.

Wallach, J. The perception of neutral colors. Scientific American, $1963,208,107-116$.

Woodworth, R. S., \& Schlosberg, H. Experimental psychology. New York: Holt, 1955.

\section{Appendix 1 \\ Lightness and Brightness Instructions Used in Experiment 2}

\section{LIGHTNESS}

In making your judgments, I want you to indicate the chip which matches the target in lightness. By lightness we mean the degree of whiteness or blackness. Consider the chips as ranging from a dark color to a light color, and choose the chip matching the color of the target.

It is very easy to confuse lightness and brightness. By brightness, we mean the degree of dimness or intensity. Lightness and brightness are similar, but they are not the same. A white surface will appear intense or dim depending on the amount of illumination, but it will still appear white. For example, a white page will appear brighter or intense in sunlight and dim indoors, but still be white in both instances.

In the present task, try to ignore brightness and judge only lightness.

\section{BRIGHTNESS}

In making your judgments, I want you to indicate the chip which matches the target in brightness. By brightness we mean the degree of dimness or intensity. Consider the chips as ranging from dim to bright, and choose the chip matching the intensity of the target.

It is very easy to confuse brightness and lightness. By lightness we mean the degree of whiteness or blackness. Brightness and lightness are similar but they are not the same. A surface may be white or black, but it will still have the same brightness if illumination does not change. For example, a white page and black print in a book both appear intense to about the same degree in direct sunlight.

In the present task, try to ignore lightness and judge only brightness.

NOTE-The relevant instructions were first read to the subject and then elaborated upon if necessary. 
Appendix 2

Questions Used in Experiment 2 to Assess Subjects' Understanding of the Concepts "Brightness" and "Lightness"

\section{PRETEST QUESTIONS}

1. Will a white page become brighter or lighter when you take it from indoors to direct sunlight? (brighter)

2. The difference in appearance between the white page and black print in a book viewed in direct sunlight is an example of different lightness or brightness? (lightness)

\section{POSTTEST QUESTIONS}

1. Does a piece of white paper and a piece of coal differ in brightness or lightness when viewed in direct sunlight? (lightness)

2. Does the snow differ in lightness or brightness when viewed at night and during the day? (brightness)

3. At sunset you must turn on a light to read by because lightness or brightness of the page decreases? (brightness)

4. House numbers are difficult to read at night because their brightness or lightness is less? (brightness)

5. Grey cats are harder to see at night than white cats because they differ in lightness or brightness? (lightness)

6. Newsprint faded by direct sunlight is more difficult to read than a fresh newspaper because of a difference in lightness or brightness? (lightness)
7. Areas of a lawn in the shade of a tree differ from areas in direct sunlight in brightness or lightness? (brightness)

8. As snow melts and becomes "dirty" it changes in lightness or brightness? (lightness)

9. Highway signs are easier to read during the day than at night because of differences in brightness or lightness? (brightness)

10. Light-grey paint and dark-grey paint are different in brightness or lightness? (lightness)

11. A black car in sunlight and a black floor indoors differ in lightness or brightness? (brightness)

12. A white coat looks white in sunlight and also by moonlight because lightness or brightness doesn't change? (lightness)

13. Shadowed areas of a wall are not different in brightness or lightness? (lightness)

14. When you shine a spotlight on a house at night the spotlighted area is different from unlighted areas in lightness or brightness? (brightness)

NOTE-The two pretest questions were given immediately after instructions, but before the experimental session. The 14 posttest questions were answered after the experimental session. The correct answer is shown in parentheses after each question.

(Received for publication September 19, 1979; revision accepted February 25, 1980.) 